\title{
Supporting women at average risk to make informed decisions about mammography when there is no "right" answer: a qualitative citizen deliberation study
}

\author{
Laura Tripp MSc, Julia Abelson PhD
}

Abstract

Background: Women are encouraged to make informed choices about mammography screening that align with their values and preferences, yet information materials developed by screening programs rarely provide complete, balanced information about screening. Through a series of deliberations with Ontario citizens, we elicited perspectives on materials developed by screening programs to support informed decision-making.

Methods: We held 4 deliberative engagement events with citizens to discuss the current evidence about mammography and informed decision-making for the general population (i.e., women not at high risk) in the context of organized screening programs. Participants reviewed and provided feedback on the educational materials currently produced by screening programs in 8 provinces (British Columbia, Alberta, Saskatchewan, Manitoba, Ontario, Quebec, Nova Scotia and Newfoundland and Labrador) and 2 territories (Yukon Territory and Northwest Territory) and identified the key features that should guide the design of these materials to optimally support informed decision-making.

Results: In general, participants viewed the educational materials as insufficient to support informed decision-making. They identified the following key features of optimal educational materials: they should be accessible, complete and accurate, and provide information on both benefits and risks of screening in a comprehensive, easy-to-understand manner. Information materials should evoke the trust of the reader, and they should be consistent across Canada.

Interpretation: Canadian women have insufficient access to reliable information sources and complete evidence about mammography screening, and, without this information, they are unable to make fully informed decisions. Canadian breast screening programs must take steps to improve the information shared with women to support informed decision-making that aligns with women's values and preferences.

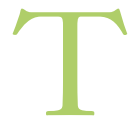
he Canadian Task Force on Preventive Health Care's 2018 recommendations on mammography screening for women at average risk recommends that women aged $50-74$ years be screened every $2-3$ years. ${ }^{1}$ Women at average risk are defined as those without a personal or family history of breast cancer who are not (and whose first-degree relatives are not) carriers of specific gene mutations (e.g., BRAC1, BRAC2) and who did not have chest radiation before age 30 years or in the previous 8 years. Unlike previous recommendations, the new recommendation is now "conditional on the relative value that a woman places on the possible benefits and harms from screening," which suggests that there is no "right" decision; rather, decisions should fit with women's values and preferences. ${ }^{1}$

To make informed decisions about mammography that align with their values and preferences, women need sufficient information about risks, benefits and available alternatives. ${ }^{2}$ Educational materials are one tool to share this information. ${ }^{3}$
Yet reviews of Canadian and international screening program materials show that most are biased toward screening and include little information about risks. ${ }^{4-9}$ A survey of Ontarians showed that women report confidence in their knowledge about screening yet do not feel they are making informed decisions. ${ }^{10}$ To support decision-making, some jurisdictions have elicited women's perspectives on educational materials, ${ }^{11,12}$ but little has been done in Canada. This paper explores the principles that should guide the development of materials to support informed decision-making about mammography screening.

\section{Competing interests: None declared.}

This article has been peer reviewed.

Correspondence to: Julia Abelson, abelsonj@mcmaster.ca

CMAJ Open 2019. DOI:10.9778/cmajo.20190102 


\section{Methods}

\section{Design}

Citizen deliberations were held to elicit citizens' values about mammography screening and how to support informed decision-making within the context of an organized screening program. Four deliberations were held to ensure that a diversity of perspectives (sociodemographic, geographic and regional) on the topic were explored. Citizen deliberations provide opportunities for citizens to participate in informed discussions about potentially difficult topics that require value-based judgments, trade-offs and decisions. ${ }^{13}$ To facilitate informed discussions, clear, balanced information on the topic of interest is provided to participants. ${ }^{14}$ Deliberative methods have been used for various health topics in Canada and internationally, including cancer screening. ${ }^{15}$

\section{Setting}

The study was set in Ontario, where the Ontario Breast Screening Program has been in place since $1990 .{ }^{16}$ Four deliberations were held. The initial deliberation was held at the provincial level; all remaining deliberations were held locally in communities selected for geographic diversity (northern, rural, urban) and mammography screening uptake (high, average and low). Deliberations were held between March 2015 and March 2016 (Table 1).

\section{Participant recruitment}

Deliberation A included men and women 18 years of age or more to allow a broad set of perspectives to be captured at the outset of the study. To ensure geographic representation, we recruited people from each of Ontario's Local Health Integration Networks. Participants were recruited by email from a previous panel led by one of the investigators (J.A.) $)^{19}$ and through the online survey panel AskingCanadians. Subsequent deliberations (B, C and D) were held in 3 Ontario communities with screen-eligible women (age 50-74 yr with no previous diagnosis of breast cancer). We recruited participants for deliberations $\mathrm{B}$ and $\mathrm{C}$ through Kijiji and newspaper advertisements. Deliberation D participants were recruited through an online survey on mammography screening. ${ }^{10}$ Varied recruitment strategies allowed us to explore the feasibility of different strategies and the extent to which they exerted different influences on the quality of the deliberation (to be presented in a separate paper) (Table 1). Potential participants completed a survey to confirm eligibility; employees of cancer screening organizations were excluded. Participants received $\$ 75$ for their participation, and travel expenses were reimbursed.

\section{Data collection}

Each deliberation lasted $0.5-1.5$ days and consisted of information sharing before and during deliberations, and largeand small-group discussions. Before the deliberations, participants received a summary of the current evidence on mammography screening (drawing on published reviews). Participants also viewed presentations by an oncologist and a family physician outlining the history of mammography, the current state of evidence and how evidence informs practice (Appendix 1, available at www.cmajopen.ca/content/7/4/ E730/suppl/DC1). Deliberation A participants viewed the presentations live (in person or via webcast); the other participants viewed a recording. The oncologist was available at

Table 1: Characteristics of citizen deliberations

\begin{tabular}{|c|c|c|c|c|c|c|c|c|c|}
\hline \multirow[b]{2}{*}{ Deliberation } & \multirow[b]{2}{*}{$\begin{array}{l}\text { Panel } \\
\text { size }\end{array}$} & \multirow[b]{2}{*}{ Location } & \multirow[b]{2}{*}{$\begin{array}{l}\text { Population } \\
(2016)^{17}\end{array}$} & \multirow[b]{2}{*}{$\begin{array}{l}\text { OBSP } \\
\text { screening } \\
\text { rate, } \%^{*}\end{array}$} & \multicolumn{4}{|c|}{ Recruitment strategy used } & \multirow[b]{2}{*}{$\begin{array}{l}\text { Brochures reviewed by small } \\
\text { group } \dagger\end{array}$} \\
\hline & & & & & $\begin{array}{l}\text { Previous } \\
\text { panel }\end{array}$ & $\begin{array}{l}\text { Print } \\
\text { advertisement }\end{array}$ & $\begin{array}{l}\text { Online } \\
\text { advertisement }\end{array}$ & $\begin{array}{l}\text { Online } \\
\text { survey } \\
\text { panel }\end{array}$ & \\
\hline A & 13 & Ontario & 13488494 & 43.2 & $x$ & & & $\mathrm{X}$ & $\begin{array}{l}\text { 1: British Columbia, } \\
\text { Newfoundland and Labrador } \\
\text { 2: Alberta, Saskatchewan }\end{array}$ \\
\hline$B$ & 12 & $\begin{array}{l}\text { Northern } \\
\text { Ontario }\end{array}$ & 107909 & 48.7 & & $X$ & $\mathrm{X}$ & & $\begin{array}{l}\text { 1: Manitoba, Quebec } \\
\text { 2: Alberta, Quebec }\end{array}$ \\
\hline C & 12 & $\begin{array}{l}\text { Southern } \\
\text { Ontario }\end{array}$ & 97496 & 59.3 & & $x$ & $x$ & & $\begin{array}{l}\text { 1: Alberta, Nova Scotia, } \\
\text { Northwest Territories } \\
\text { 2: British Columbia, } \\
\text { Saskatchewan, Yukon Territory }\end{array}$ \\
\hline $\mathrm{D}$ & 12 & $\begin{array}{l}\text { Greater } \\
\text { Toronto Area }\end{array}$ & 2731571 & 34.9 & & & & $\mathrm{X}$ & $\begin{array}{l}\text { 1: Manitoba, Newfoundland } \\
\text { and Labrador, Northwest } \\
\text { Territories } \\
\text { 2: Quebec, Nova Scotia, } \\
\text { Yukon Territory }\end{array}$ \\
\hline $\begin{array}{l}\text { Note: OBSP = } \\
{ }^{*} \text { Age-standardi } \\
2010 / 11 .{ }^{18} \\
\text { †All groups als }\end{array}$ & $\begin{array}{l}\text { tario } \mathrm{Br} \\
\mathrm{d} \text { propo } \\
\text { eviewec }\end{array}$ & $\begin{array}{l}\text { ast Screening } P \\
\text { on of screen-eli } \\
\text { he OBSP broch }\end{array}$ & $\begin{array}{l}\text { ram. } \\
\text { le women ag } \\
\text { and invitatic }\end{array}$ & $\begin{array}{l}\text { 50-74 year } \\
\text { etter. }\end{array}$ & at average & who had at lea & mammography & ening e & mination with the OBSP in \\
\hline
\end{tabular}


the outset of all deliberations to answer questions. Additional information was shared by the facilitator during deliberations.

Both authors attended all deliberations along with 2 graduate students. L.T. and the graduate students took notes. J.A. facilitated the large-group discussions, and both authors and 1 of the graduate students facilitated the small-group discussions. A facilitator's guide was used (Appendix 2, available at www.cmajopen.ca/content/7/4/E730/suppl/DC1). Both authors are women with a family history of breast cancer. J.A. was eligible for mammography screening at the time of the study and was making screening decisions. This was disclosed to participants given its relevance to discussions; family history was not disclosed.

The questions guiding the deliberations were: 1) What citizen and patient values should be reflected in breast cancer screening programs? and 2) What principles should guide the development of materials to support informed decisionmaking about mammography screening? This paper focuses on the second question, which was addressed primarily through a small-group activity. The first question was addressed in a separate paper. ${ }^{20}$ Participants were asked to review educational materials developed by provincial and territorial screening programs, to provide feedback on these materials and to reflect on how they could support informed decision-making.

The websites of the 12 Canadian provinces and territories with organized breast screening programs (all but Nunavut) were reviewed by L.T. to identify English-language materials readily available to the public (Appendix 3, available at www. cmajopen.ca/content/7/4/E730/suppl/DC1). Materials not accessible online were requested by email. Brochures were collected from 10 screening programs; materials were not available from Prince Edward Island or New Brunswick. The material was reviewed by at least 2 groups; all groups reviewed the Ontario Breast Screening Program pamphlet and invitation letter.

\section{Data analysis}

The deliberations were audiorecorded by L.T. or the graduate students, transcribed verbatim by McMaster students and verified by L.T. We used NVivo 12 (QSR International) to manage the data analysis. We analyzed the transcripts using the procedures of qualitative description, which are ideally suited for studies focused on identifying participants' perceptions and perspectives rather than on developing theory. ${ }^{21,22}$ The coding scheme was developed iteratively by the authors during the analysis of the first deliberation and refined as data were reviewed and new themes identified, confirmed or rejected through constant comparison both within and across transcripts. Themes were grouped to form the core principles presented here following discussion between the authors. The authors discussed the coding throughout to enhance reliability. Although the number of panels held was an a priori decision, by the fourth panel, few new themes were emerging, which suggested that saturation was reached.

\section{Ethics approval}

The study was approved by Hamilton Integrated Research Ethics Board.

\section{Results}

All 56 people invited consented to participate across the 4 deliberations. Seven people subsequently cancelled because of scheduling conflicts; thus, 49 people participated. Deliberation A included 5 men; all other participants were women. Of the 44 female participants, 5 (11\%) had never had mammography. Over one-third (19 [39\%]) of participants reported that a close family member had received a diagnosis of breast cancer (Table 2). Deliberations lasted 0.5-1.5 days.

\section{Core principles of program materials}

Through discussion and review of program materials, participants highlighted a series of core principles that should guide the development of future screening materials (Table 3).

\section{Accurate, evidence-based}

Participants felt strongly that screening program materials must be, at their core, evidence based and accurate. Some questioned the evidence presented in existing program materials, in many cases feeling that materials were incomplete, lacked sufficient information about screening risks or placed inaccurate emphasis on screening benefits. Participants recognized uncertainty in the evidence and encouraged screening programs to acknowledge this. Materials that did not portray mammography as a "perfect" test were viewed positively.

Accuracy was described as an integral feature of trustworthiness. Participants felt that their trust in an organization was eroded when materials included imbalanced information or language that was "leading."

\section{Comprehensive}

Participants hoped women would speak with health care providers about screening but knew this was not always possible. Since screening program materials may be a woman's only source of information, participants emphasized that these materials needed to be comprehensive. Although they understood the variability in the amount of information women need to feel informed, they felt it best to err on the side of comprehensiveness. Materials should be structured so readers can easily and quickly locate information of interest using tables of contents, alternatives to text (e.g., tables, graphs, infographics), question-and-answer formats or strong headings.

\section{Choice}

Participants valued materials that emphasize mammography screening as a choice, not an expectation. Furthermore, they wanted materials focused on supporting women to make choices that fit their values. The Quebec brochure's tagline, "It's your decision," was identified by many as a good example of this. In contrast, participants felt other materials conveyed the message that it is assumed and expected that women will 


\begin{tabular}{|c|c|c|c|c|c|}
\hline \multicolumn{6}{|l|}{ Table 2: Participant characteristics } \\
\hline \multirow[b]{2}{*}{ Characteristic } & \multicolumn{5}{|c|}{ Deliberation; no. (\%) of participants } \\
\hline & A & B & C & $\mathrm{D}$ & Total \\
\hline \multicolumn{6}{|l|}{ Demographic characteristics } \\
\hline \multicolumn{6}{|l|}{ Age, yr } \\
\hline$\leq 39$ & 1 & 0 & 0 & 0 & $1(2)$ \\
\hline $40-49$ & 1 & 0 & 0 & 0 & $1(2)$ \\
\hline $50-59$ & 5 & 9 & 8 & 7 & $29(59)$ \\
\hline $60-69$ & 4 & 3 & 4 & 4 & $15(31)$ \\
\hline$\geq 70$ & 2 & 0 & 0 & 1 & $3(6)$ \\
\hline \multicolumn{6}{|l|}{$\begin{array}{l}\text { Highest level of education } \\
\text { completed }\end{array}$} \\
\hline No schooling & 0 & 1 & 0 & 0 & $1(2)$ \\
\hline Elementary school & 0 & 1 & 0 & 0 & $1(2)$ \\
\hline High school & 2 & 2 & 2 & 0 & $6(12)$ \\
\hline Completed some postsecondary & 0 & 0 & 0 & 4 & $4(8)$ \\
\hline College & 3 & 2 & 6 & 2 & $13(26)$ \\
\hline Bachelor's degree & 3 & 5 & 3 & 5 & $16(33)$ \\
\hline $\begin{array}{l}\text { Postgraduate training or } \\
\text { professional degree }\end{array}$ & 4 & 1 & 1 & 1 & $7(14)$ \\
\hline No response & 1 & 0 & 0 & 0 & $1(2)$ \\
\hline \multicolumn{6}{|l|}{ Income, \$ } \\
\hline$<20000$ & 1 & 1 & 1 & 0 & $3(6)$ \\
\hline $20000-39999$ & 0 & 2 & 1 & 1 & $4(8)$ \\
\hline $40000-59999$ & 0 & 1 & 2 & 2 & $5(10)$ \\
\hline $60000-79999$ & 2 & 3 & 5 & 1 & $11(22)$ \\
\hline $80000-99999$ & 1 & 1 & 0 & 3 & $5(10)$ \\
\hline$\geq 100000$ & 7 & 0 & 2 & 3 & $12(24)$ \\
\hline Prefer not to answer & 2 & 4 & 1 & 2 & $9(18)$ \\
\hline \multicolumn{6}{|l|}{ Experience with cancer } \\
\hline $\begin{array}{l}\text { Personal history of cancer other } \\
\text { than breast cancer }\end{array}$ & 2 & 1 & 1 & 2 & $6(12)$ \\
\hline $\begin{array}{l}\text { History of breast cancer in close } \\
\text { family member }\end{array}$ & 2 & 4 & 8 & 5 & $19(39)$ \\
\hline $\begin{array}{l}\text { Never had mammography }(n= \\
44)^{*}\end{array}$ & 0 & 2 & 1 & 2 & $5(11)$ \\
\hline
\end{tabular}

be screened. For example, materials often focus on what to expect at screening appointments. Although this information is important for women who choose to be screened, participants felt strongly that it should be complementary to the main focus - supporting women to make a decision - and that information also be included for those who choose not to be screened.

\section{Accessible}

Participants emphasized the importance of information's being accessible in terms of both presentation and format- ting (e.g., the font size must be appropriate so materials can be read) and in how the information is communicated and distributed. Materials should be shared with women in multiple ways (e.g., mailings from screening programs, included with health card renewal letters), and information should be available in public places where women congregate (e.g., spas, recreation centres, libraries) and shared with women before age 50 so they are aware of the choice they will need to make. Participants identified primary care providers as important supports for informed decision-making but acknowledged that not all women have a primary care 
Table 3: Core principles that should guide the development of future screening materials, with illustrative comments by participants*

Principle Illustrative quote

Accurate and evidence-based

"The best way you protect your health is by getting a mammogram every 2 years." The best way to protect my health? Well, there's lots of ways to protect my health, and they have nothing to do with getting mammograms. So that may be a big statement to make; it's not entirely true. (PB3)

Because [screening organizations] have that credibility, I think ... the onus should be on them to be more balanced. (PA10)

I think that if [the evidence is] not in the pamphlets, then it hurts the credibility of the organization. (PA4)

Comprehensive I have to read this and think "This is what I want to do." Not "Hmm, maybe I need to research more." It should give me everything I need as a good starting point to make a decision. (PB4)

You see here, and they are all guilty of the same darn thing — are mammograms safe? Do they hurt? All they do is talk to the actual mammogram ... not about risk, ever, really, anywhere. (PA2)

It's almost like it needs an index at the front that has the categories of information that are in there. So, if all you're looking for is how should I prepare for my appointment, you go to page 5. If it's what should I be expecting from my doctor, it's a little bit of a table of contents, almost, that would guide you through it. Because I think there's a lot of good information in here, but I agree with you, [the chance of] anybody who would actually sit down and read through the whole thing is probably fairly minimal. But it's like "Well, there's the one thing that l'm wondering about that I would like to find." (PD3)

Choice Just enough [information] to make that informed decision and choice, that's what I value. Informed choice. Educated decisions. (PB1) I think the only other thing ... [is] sort of asking the question when you get the letter of how to decide if breast cancer screening is right for you. So it's some considerations, like even a hint, at there are some things that you should think about. How to decide if it's right for you. And maybe it's 4 or 5 provocative questions that you should be asking yourself. (PD3)

Don't sell me on the mammography, give me the information so I can make a choice. (PA5)

Accessible The font is clearly not for the 50-74 age group, and I find that so annoying because look at who is trying to read this. And we hate getting our reading glasses out. (PC5)

Consistent When I go to a McDonald's or [Tim Horton's], I want my coffee to be the same right across Canada. So when I go for medical treatment - and that's more important to me than my coffee - I want to be able to get the same information if I live in Ontario or [if] my child goes to the east coast for school and stays there, I want to know that she's getting the same [information] as I am. (PC6)

This should be a national discussion, it doesn't really matter where we live, we're all going to be affected the same way. (PD11)

Transparent

This idea of treating as many people as possible - that's totally in conflict with the idea of supporting people in making a choice and a decision, because the [earlier] part is saying that we're going to keep pushing people, regardless ... our goal is to get as many people as possible through screening, if they decide it's appropriate for them or not. (PD8)

This one that does the risks and the benefits is nice because I think I tend to believe [it] more. If they give you the benefits and they give you the risks, too, it's almost giving it more credibility because they are telling you what the risks or the cons are as well. So, to me, this gives this more credibility. (PB4)

${ }^{\star}$ Participants are identified by deliberation (A, B, C or D) and participant number (e.g., A1). 
provider, and care providers face barriers (e.g., lack of awareness of evidence, lack of time) when having these discussions. Thus, written materials are still necessary to ensure information is accessible.

\section{Consistent}

Although all materials reviewed were from Canadian screening programs, little consistency was found in the messaging, framing of the evidence and amount of information provided. The lack of consistency concerned participants, as most women will only ever see their province's or territory's material and, thus, would not be aware of the variability across the country or understand their information might be incomplete relative to what is provided elsewhere. This was an equity consideration for some: all women in Canada should have access to the same high-quality information, regardless of location. Participants suggested that consideration be given to developing a single information resource that could be tailored for use across the country.

\section{Transparent}

As a primary source of information about mammography for women, screening programs play a key role in informed decision-making. Some participants were skeptical, however, that programs could provide balanced information. Participants perceived that the very goal of the programs screening people for cancer - makes it in their interest to encourage screening rather than to provide information on potential harms. Participants expected screening programs to move beyond these inherent conflicts. They spoke of screening programs as credible organizations that need to be more balanced and share all information. Some felt that screening programs were not the optimal source of information and suggested that other bodies may be better suited to this role. Regardless of who is providing the information, participants wanted organizations to be transparent about their goals and what conflicts might exist in pursuing these goals, and about the screening information available. In practice, this would mean providing detailed information, including risks, not just the information that shows screening in a positive light.

\section{Formatting considerations}

Participants also provided feedback on the look of the program materials (Table 4). Key considerations included ensuring images were generic and relevant to the target audience, and did not overpower the text information. They wanted information provided in user-friendly ways that captured readers' attention. Information should also be provided in a multitude of ways to accommodate different learning styles.

\section{Interpretation}

This study examined how breast cancer screening programs' materials can support informed decision-making. Study participants felt that existing program materials were insufficient for this purpose. They wanted materials to be accessible, complete and accurate, and to evoke readers' trust, providing information on benefits and risks of screening in a comprehensive, easy-to-understand way. Furthermore, they identified the need for a single set of materials to be developed for use across all Canadian screening programs.

Our results reinforce previous work carried out in Ontario and other jurisdictions showing that screen-eligible women do not feel they are making informed decisions ${ }^{23}$ and that existing program materials do not provide balanced information about screening. ${ }^{7-9}$ This was echoed by our study participants, who were largely unaware of current evidence about mammography screening before attending the deliberations.

At a time when the responsibility for making decisions about mammography screening is being placed firmly into the hands of women, and as the balance tips more toward acknowledging that there is no right choice when it comes to screening, Canadian women need accurate, balanced and accessible educational materials to support their decisions. Further research is needed in this area to understand how women can be supported to make informed decisions, including how these findings can be implemented by screening programs.

\section{Limitations}

This study is not without limitations. Deliberation studies require a substantial time commitment from participants, and participation tends to be skewed toward more highly educated, wealthier participants even when participation incentives are included. Compared to the general Ontario population, ${ }^{17}$ our study participants were more likely to have completed at least some postsecondary education $(82 \% \mathrm{v}$. $45 \%)$ and to have an annual family income of more than $\$ 60000$ (57\% v. 32\%). The study included Ontarians only, and thus may not reflect the views of women of screening age in other regions.

\section{Conclusion}

The Canadian Task Force on Preventive Health Care has called on health care providers, screening programs and others to help women consider their values and preferences to make informed decisions about mammography screening. An important step in this process is to ensure that the information available to women who are making decisions is current, complete and consistent to support fully informed screening decisions. This information should also emphasize that screening is a choice. Reaching agreement on how to respond to the principles identified in the current study will present challenges for the screening community given the current decentralized approach to the development and dissemination of screening materials. Nevertheless, our study participants were clear in their desire for consistency in the types of materials provided to women across Canada to help ensure equitable access to screening information and evidence. Screening program decision-makers and others contributing to this field need 


\begin{tabular}{|c|c|}
\hline $\begin{array}{l}\text { Area of } \\
\text { focus }\end{array}$ & Suggestion \\
\hline Formatting & $\begin{array}{l}\text { - Use of bold or highlighting (colour) to attract the reader's eye is helpful for } \\
\text { key points } \\
\text { - Font size must be large enough to be easily read; consider your primary } \\
\text { audience (e.g., women > } 50 \mathrm{yr} \text { ) when determining the formatting of the } \\
\text { materials } \\
\text { - Use colour to catch the reader's eye - something needs to draw them in, } \\
\text { so the materials don't seem too technical or "dull" } \\
\text { - Do not provide too much information on } 1 \text { page; if including information on } \\
\text { both sides of a page (e.g., a letter), be certain that the reader knows to turn } \\
\text { the page over } \\
\text { - Cover needs to grab the attention of the reader }\end{array}$ \\
\hline Statistics & $\begin{array}{l}\text { - Present statistics for all issues, even if there is uncertainty in the data } \\
\text { (e.g., for overdiagnosis) } \\
\text { - Provide comparisons (e.g., mortality rates for screened and unscreened } \\
\text { women) to put information into context } \\
\text { - Present the information in different ways to ensure understanding } \\
\text { (e.g., numbers, charts, graphs, infographics) } \\
\text { - Present the statistics as number in } 100 \text { or } 1000 \text { as those are the easiest } \\
\text { numbers to relate to }\end{array}$ \\
\hline Images & $\begin{array}{l}\text { - Use images sparingly } \\
\text { - Images can be used to get key information across (e.g., photographs of a } \\
\text { mammography machine) } \\
\text { - Avoid photographs of people, where possible, so all citizens can see } \\
\text { themselves in the photographs } \\
\text { - When including photographs of people, ensure that the diversity of the } \\
\text { population is captured and that the photographs represent the target } \\
\text { audience (women aged } 50-74 \mathrm{yr} \text { ) }\end{array}$ \\
\hline $\begin{array}{l}\text { Structure of } \\
\text { information }\end{array}$ & $\begin{array}{l}\text { - Use headings, table of contents to make information easy to find } \\
\text { - Consider a questions-and-answer approach throughout the materials, or a } \\
\text { frequently asked questions section } \\
\text { - Providing information in a series of short points (bullet form) can help the } \\
\text { reader get through a large amount of information }\end{array}$ \\
\hline Language & $\begin{array}{l}\text { - Consider carefully what language to use when describing risks and benefits } \\
\text { (e.g., pros and cons, harms and benefits) } \\
\text { - Ensure that the language supports choice } \\
\text { - Be aware of the reading level of the text }\end{array}$ \\
\hline Source & $\begin{array}{l}\text { - Consider other sources of information in addition to print materials: social } \\
\text { media, websites, email campaign, in-person campaigns, television } \\
\text { - Trusted media personalities (e.g., daytime talk show hosts) for the age } \\
\text { group could also be engaged to share the evidence }\end{array}$ \\
\hline
\end{tabular}

to work toward finding common ground to support informed decision-making in line with the principles outlined in the present study.

\section{References}

1. Klarenbach S, Sims-Jones N, Lewin G, et al.; Canadian Task Force on Preventive Health Care. Recommendations on screening for breast cancer in women aged 40-74 years who are not at increased risk for breast cancer. CMA7 2018; 190:E1441-51.

2. Rimer BK, Briss PAS, Zeller PK, et al. Informed decision making: What is its role in cancer screening? Cancer 2004;101(Suppl):1214-28.

3. Stacey D, Légaré F, Lewis K, et al. Decision aids for people facing health treatment or screening decisions. Cochrane Database Syst Rev 2017;(4):CD001431.

4. Attena F, Cancellieri M, Pelullo CP. Scarce information about breast cancer screening: an Italian websites analysis. Medicine (Baltimore) 2016;95:e5615.

5. Jørgensen KJ, Gøtzsche PC. Content of invitations for publicly funded screening mammography. BM7 2006;332:538-41.

6. Kearney AJ, Polisena J, Morrison A. A review and comparative analysis of information targeted to the general public on the websites of breast screening programs in Canada. Healthc Policy 2017;13:57-67.
7. Gummersbach E, Piccoliori G, Zerbe CO, et al. Are women getting relevant information about mammography screening for an informed consent: a critical appraisal of information brochures used for screening invitation in Germany, Italy, Spain and France. Eur 7 Public Health 2010;20:409-14.

8. Zapka JG, Geller BM, Bulliard JL, et al.; IBSN Communications Working Group. Print information to inform decisions about mammography screening participation in 16 countries with population-based programs. Patient Educ Couns 2006;63:126-37.

9. Jørgensen KJ, Gøtzsche PC. Presentation on websites of possible benefits and harms from screening for breast cancer: cross sectional study. BM7 2004;328:148.

10. Abelson J, Tripp L, Brouwers MC, et al. Uncertain times: a survey of Canadian women's perspectives toward mammography screening. Prev Med 2018;112: 209-15.

11. Forbes LJ, Ramirez AJ; Expert group on Information about Breast Screening. Offering informed choice about breast screening. 7 Med Screen 2014;21: 194-200.

12. Hersch J, Barratt A, Jansen J, et al. Use of a decision aid including information on overdetection to support informed choice about breast cancer screening: a randomised controlled trial. Lancet 2015;385:1642-52.

13. Blacksher E, Diebel A, Forest PG, et al. What is public deliberation? Hastings Cent Rep 2012;42:14-7.

14. Wilson MG, Nidumolu A, Berditchevskaia I, et al. Identifying approaches for synthesizing and summarizing information to support informed citizen deliber- 
ations in health policy: a scoping review. 7 Health Serv Res Policy 2019 Sept. 14 [Epub ahead of print]. doi: 10.1177/1355819619872221.

15. Rychetnik L, Carter SM, Abelson J, et al. Enhancing citizen engagement in cancer screening through deliberative democracy. 7 Natl Cancer Inst 2013;105: $380-6$.

16. Breast cancer screening in Canada: environmental scan. Toronto: Canadian Partnership Against Cancer; 2018.

17. Census profile, 2016 census. Ottawa: Statistics Canada; 2017, updated 2019 June 18. Available: www12.statcan.gc.ca/census-recensement/2016/dp-pd/prof/ index.cfm?Lang=E (accessed 2019 May 6).

18. Ontario Breast Screening Program, 2011 report. Toronto: Cancer Care Ontario; 2013.

19. Abelson J, Bombard Y, Gauvin FP, et al. Assessing the impacts of citizen deliberations on the health technology process. Int 7 Technol Assess Health Care 2013; 29:282-9.

20. Abelson J, Tripp L, Sussman J. 'I just want to be able to make a choice': results from citizen deliberations about mammography screening in Ontario, Canada. Health Policy 2018;122:1364-71.

21. Sandelowski M. Whatever happened to qualitative description? Res Nurs Health 2000;23:334-40.

22. Sandelowski M. What's in a name? Qualitative description revisited. Res Nurs Health 2010;33:77-84.

23. Abelson J, Tripp L, Brouwers MC, et al. Uncertain times: a survey of Canadian women's perspectives toward mammography screening. Prev Med 2018;112: 209-15.

Affiliations: Department of Health Research Methods, Evidence, and Impact (Tripp, Abelson) and Centre for Health Economics and Policy Analysis (Abelson), McMaster University, Hamilton, Ont.
Contributors: Julia Abelson conceived and designed the study. Laura Tripp led the analysis and interpretation of data with Julia Abelson's input on the original analysis plan. Laura Tripp drafted the manuscript, and Julia Abelson revised it critically for important intellectual content. Both authors contributed substantially to the acquisition of the data, approved the final version to be published and agreed to be accountable for all aspects of the work.

Funding: This study was funded by the Government of Ontario through a Ministry of Health and Long-Term Care Health System Research Fund grant (grant 02045) and the Ontario SPOR SUPPORT Unit, which is supported by the Canadian Institutes of Health Research and the Government of Ontario.

Acknowledgements: The authors thank all participants in the citizen deliberations for sharing their perspectives, Dr. Jonathan Sussman and Dr. Cathy Risdon for their participation in the public talk on breast cancer screening, the Labarge Optimal Aging Initiative and the McMaster Health Forum for their assistance with and support of this event, and Melodie Yun-Ju Song and Sarah Boesveld for their assistance with the deliberations.

Disclaimer: The views expressed in this paper are the views of the authors and should not be taken to represent the views of the funders.

Supplemental information: For reviewer comments and the original submission of this manuscript, please see www.cmajopen.ca/content/7/4/ E730/suppl/DC1. 